\title{
ESPAÇO PÚBLICO E PRIVADO NA OBRA “A CONDIÇÃO HUMANA" - DE HANNAH ARENDT E A EXPERIÊNCIA DO PROJETO ESCOLA LIVRE DE FILOSOFIA
}

Bernardo Geraldo Domingos

Graduando Em Ciência Política - Instituto De Ciência Política

Universidade De Brasília (Unb)

\section{Resumo}

Hannah Arendt, no seu livro "A Condição Humana" aponta que o surgimento da cidade-estado, gerou uma espécie de "segunda vida" para os homens, separando a existência dos homens em dois campos: a vida privada, e a vida pública, entre o que lhe é próprio (idion) o que lhe é comum (koinon), a polis, portanto gerou um espaço de discussão, de debate e que eliminava as organizações com base no parentesco. Além disso, esse seria um local no qual os indivíduos se reconhecem e delimitam os seus espaços. Segundo a autora, viver na polis, no espaço público significava, viver dentro das discussões, utilizando-se dos discursos, das palavras e da persuasão e nunca, de forma alguma recorrer ao uso da violência. O projeto de extensão Escola Livre de Filosofia, vinculado ao Departamento de Filosofia da Universidade de Brasília (UnB), tem por metodologia de trabalho, ampliar o espaço público, gerando e proporcionando debates em diversos seguimentos da sociedade, com os mais diversos públicos; com esse trabalho entendemos ser possível, difundir conceitos e valores para sociedade, possibilitar novas reflexões e contribuir para que a palavra, a discussão, a persuasão retome seu espaço e afaste a violência. Este trabalho pretende discutir os conceitos da autora, bem como discutir novos espaços e novas possibilidades de ampliar os espaços públicos de discussão e debates.

Palavras - Chave: Espaço Público, Espaço Privado, Ação Política e Violência. 
Na obra, a "A Condição Humana" de Hannah Arendt, são apresentadas pela autora diversas concepções e conceitos, neste trabalho especificamente iremos nos deter basicamente nas definições acerca do que significa para a autora o "espaço público" e "espaço privado", exposto no capítulo segundo da obra, no subtítulo "O Homem: Animal Social ou Político". Utilizamos esta distinção feita pela autora, para nos orientarmos e estabelecermos, relações como o Projeto da Escola Livre de Filosofia.

Dessa forma, primeiramente faremos, uma breve apresentação do projeto, demonstrando em que consiste, sua metodologia, sua forma de atuação, para em seguida, traçarmos as relações com a obra de Hannah Arendt, mostrando o quanto esse pensamento nos auxiliou teoricamente para fundamentarmos e estabelecermos as bases de ação do projeto.

O Projeto da escola Livre de Filosofia, é vinculado ao Departamento de Filosofia da Universidade de Brasília (UnB), tem como coordenador o professor Rogério Alessandro de Mello Basali; o projeto consiste basicamente em ação de extensão e pesquisa, visando a promoção de maior interatividade com setores da sociedade que não possuem uma relação muito próxima com a Filosofia e com a Política, no que diz respeito as suas teorias. Ou seja, o trabalho do projeto é levar essas áreas do conhecimento para mais perto do dia-a-dia das pessoas, promovendo assim, um espaço de reflexão que extrapola o campo da Universidade e do ambiente Acadêmico. Assim sendo, acreditamos que com esse projeto podemos criar novos campos de interação com a sociedade, possibilitar e criar novos espaços de discussão, divulgar o conhecimento, e também adquirir conhecimento. Por isso, é fundamental, para levarmos e criarmos esses debates, a nossa pesquisa e a orientação para que o projeto possa de fato contribuir para a melhoria da sociedade e atender aos seus anseios e demandas, com isso acreditamos também, que o projeto cumpre perfeitamente os propósitos estabelecidos pela universidade, que vem a ser o "Ensino, a Pesquisa e a Extensão".

“Extensão, sob o princípio constitucional da indissociabilidade entre ensino, pesquisa e extensão, é um processo interdisciplinar, educativo, cultural, científico e político que promove a interação transformadora entre Universidade e outros setores da sociedade. (Minuta Resolução da Câmara de Extensão da Universidade de Brasília 01/2013- Artigo 1 - pág. 1)”. 
Realizamos de forma periódica, encontros internos com os membros do grupo, em conjunto com o coordenador, e sob sua orientação, realizamos os trabalhos de pesquisa; promovemos encontros com outros grupos de pesquisa e professores de diversas áreas do conhecimento, além de promovermos encontros fora da universidade para atender aos mais diversos públicos que tenham ou não alguma relação com a Filosofia ou como o ambiente acadêmico; satisfazendo dessa forma outro requisito estabelecido pela universidade.

\footnotetext{
"As atividades de extensão na Universidade de Brasília - UnB têm como objetivo primordial promover uma relação universidade/sociedade mutuamente transformadora, articulando ensino e pesquisa, por meio da arte, ciência, tecnologia e inovação com vistas ao desenvolvimento social. (Minuta Resolução da Câmara de Extensão da universidade de Brasília 01/2013- Artigo 2 - pág.1)".
}

Portanto, o projeto, por sua constituição, por sua característica, visa promover novos campos de interatividade, novos campos de debate, visa ampliação de espaços, para que tanto a Filosofia, quanto a política possa ser exercida, criada, pensada, organizada, nossa experiência nos mostrou e nos tem mostrado que há a necessidade de criação desses espaços, para que de fato se estabeleça uma maior compreensão do que vem a ser o campo da política e para que haja o alargamento dos espaços públicos que como veremos são muito preciosos no pensamento de Hannah Arendt. Passemos assim, a partir de agora, a examinar, mais detidamente os conceitos de espaço público e privado em sua obra.

Hannah Arendt estabelece que a ação seja prerrogativa exclusiva dos homens, pois esta só faz sentido, e só é possível, mediante uma relação que ela estabelece com o outro com o próximo, como a autora diz um homem que trabalhasse e construísse num mundo habitado somente por ele mesmo, teria perdido a sua qualidade especificamente humana, nem um deus, nenhum animal é capaz de ação, e só a ação depende inteiramente da constante presença de outros (Condição Humana- Capítulo II pág. 31). Dessa forma, quando o, projeto se dispõe, a dialogar, com outras pessoas, a estabelecer novas relações dentro ou fora do ambiente acadêmico, ele segue essa prerrogativa estabelecida por Hannah Arendt, ou seja, o de criar ações, e não ficar num debate isolado, trancafiado, ele se dispõe a agir, ele se dispõe a criar. 
Durante essa ação, durante esse ato, tanto o projeto, quanto as pessoas que irão interagir com o projeto, saem dos seus lugares próprios e privados e passam a estabelecer dentro e a partir dessa ação, espaços comuns de debate, na qual a principal característica é gerar um fundamento de igualdade entre todos aqueles que estão participando, princípio esse que norteia a concepção de espaço público e político de Hannah Arendt.

Outro aspecto importante e que convêm mencionarmos é o fato de que quando ocorre a ação, também escapamos aos modelos impostos e que nos condicionam em sociedade, agindo estabelecemos novos critérios de comportamento e rompemos com velhas estruturas estabelecidas, ou seja, repensamos o espaço no qual vivemos, mas para chegarmos a essa ação, criarmos essas estruturas, há um movimento anterior, que vem a ser o debate, a discussão, a criação, é isso o que o Projeto da Escola Livre se propõe, ele não se propõem a ditar as condutas, a normatizar os comportamentos, ele se propõem a possibilitar a "arena" onde os debates possam ocorrer. Assim guardadas as devidas proporções é como se o projeto de certa forma buscasse reviver os aspectos ressaltados pela autora, do modo de se viver na polis grega.

Isto é, o ato de num determinado espaço de tempo das nossas vidas, nos dedicarmos a uma atividade de pensar questões que não são estritamente úteis ou guiadas pela necessidade, mas de abrirmos espaço, para a construção de um pensamento fundado a partir da ociosidade e resgatar um valor de liberdade, que para os gregos só seria possível, na esfera pública. Espaço no qual, todos nós deixamos de pensar nas nossas necessidades individuais e passamos a pensar no âmbito público, do coletivo, e é nesse espaço que necessariamente se dará o reconhecimento do outro.

\footnotetext{
“A polis diferenciava-se da família pelo fato de somente conhecer iguais, ao passo que a família era o centro da mais severa desigualdade. Ser livre significa ao mesmo tempo não estar sujeito às necessidades da vida nem ao comando de outro e também não comandar. Não significava domínio, como também não significava submissão.” (ARENDT 2007: pág. 41)
}

O projeto Escola Livre de Filosofia, procura fazer com que a universidade, a academia, não se torne um espaço, restrito e privado, não que isso esteja acontecendo, 
mas, porque há o entendimento de que existe essa tensão entre o público e o privado permeando constantemente as nossas relações, dessa forma o projeto procura, manter uma postura de que se queremos ampliar as nossas liberdades, isso deve ser feito na medida em que conseguimos ampliar, os espaços públicos de debate. Se a universidade pretende ser um espaço de liberdade, ela precisa se dispor aos debates, a criar mecanismos no qual as suas discussões não fiquem restritas apenas aos seus membros, ela precisa estar em diálogo constante com toda a sociedade. Pois, não havendo essa ampliação dos espaços, das esferas públicas, há uma tendência a tornar esses espaços em espaços privados, e como notamos, criar espaços privados é criar espaços de desigualdades, e isso é exatamente o inverso do que a universidade se dispõe a realizar, isso é contrário àquilo que vem a ser o papel da universidade. Dessa forma o projeto procura através da universidade, utilizando das suas ferramentas, dos seus atributos, promover aquilo que por excelência é o que fundamenta as universidades públicas brasileiras em especial e em particular a Universidade de Brasília.

Notemos que, procuramos valorizar e ressaltar a denominação de instituição pública, pública para nós no sentido de que deve promover a igualdade entre os membros e que deve ter por prerrogativa levar a toda sociedade esse caráter igualitário.

Ou seja, de certa forma é como se o projeto buscasse um ideal, presente em Hannah Arendt, de reviver algo já um tanto quanto esquecido, um anseio pela liberdade, que a autora foi buscar lá na polis grega, já tão distante de nós. Porém, constantemente, sempre temos que estar atentos a não perdermos esse horizonte, que segundo a autora pode significar, cairmos sob o julgo do totalitarismo. Pode soar como ingênuo ou supérfluo a ação promovida pelo projeto, mas é esse tipo de ação com caráter até mesmo singelo que pode revelar e resgatar princípios que estão se perdendo e que cada vez mais vem conduzindo a nossa sociedade à violência e a buscar medidas totalitárias, evitando a experiência do diálogo e do debate.

Buscamos assim, com o Projeto Escola Livre de Filosofia, revitalizar e trazer a tona, a distinção demonstrada por Hannah Arendt, entre espaço público e privado, e que de acordo com o seu pensamento é o cerne, a raiz da constituição da polis grega e do sujeito político.

Com a fundação da polis grega o homem passa ter, segundo a autora, uma espécie de duas vidas, isto é, há aquilo que lhe é próprio (Idion) e o que lhe é comum 
(Koinon), e passar a ter no espaço público a ação (praxis) e o discurso (lexis), são esses mecanismos, são essas praticas entre os gregos membros da polis, que segundo a autora, constitui o ser político. O ser político é esse sujeito capaz de dialogar, como os outros, de reconhecer os outros, capaz de discutir e debater, criar e negociar acordos, perceber o espaço onde se encontra. Abarcando esse conjunto de fatores Hannah Arendt aponta o grande valor desse momento, que vem a ser o encontro entre a ação e o discurso, com o intuito claro e exclusivo de afastar a violência, ora aquilo que se cria a partir do diálogo, que é construído em conjunto com os demais, reconhecendo o outro. Nesse espaço a única "arma" permitida é a retórica, a técnica do convencimento, da persuasão, na polis grega, não era admitida nenhum tipo de prática violenta, como forma de impor aos seus pares, aos seus iguais, e fazer valer os seus interesses frente aos dos demais. Para se conquistar esses objetivos o único meio é o do discurso e o da palavra.

\footnotetext{
"O ser político, o viver numa polis, significava que tudo era decidido mediante a palavras e persuasão, e não através da força ou da violência. Para os gregos, forçar alguém mediante violência, ordenar ao invés de persuadir, eram modos pré-políticos de lidar com as pessoas, típicos de vida fora da polis, característicos do lar e da vida em família, na qual o chefe da casa imperava com poderes incontestes e despóticos..." (ARENDT 2007: pág.35 e36).
}

Por assim dizer, compreendemos que o Projeto da Escola livre de Filosofia, busca contribuir para desenvolver e colaborar a para a formação desse sujeito político, obviamente guardadas as devidas, distinções existentes por conta do tempo que nos separa da polis grega, mas contribuir para formar esse sujeito em pleno século XXI, contribuir para que essa luminosidade pela busca da liberdade, não se apague, e para afastar a sombra da violência e do totalitarismo, que ronda teimosamente as nossas sociedades.

"Em que pese isso, a contrapartida da despolitização do social, a politização da ação e da palavra livres, tem muito a nos dizer. É mais uma vez contra o sombrio pano de fundo do totalitarismo e das ditaduras que brilha a reflexão arendtiana. Há no que ela diz uma luminosidade que não podemos deixar apagar: a paixão pela liberdade." (OLIVEIRA 2013: pág. 135). 
Como sabemos, a violência é o oposto da política, onde falta política, sobra a violência, onde falta a discussão e o debate, reforçam-se os elementos constituintes da intolerância, onde falta o conhecimento, sobra espaço, para o abuso e a submissão. $O$ campo do exercício da política é o espaço onde se busca eliminar, o espaço da violência e da tirania, do abuso do poder, por isso insistimos na criação e na promoção de mais espaços públicos que possam reforçar o debate, no qual seja evidenciado o caráter de igualdade entre os indivíduos, por isso esse esforço de criar esses espaços como os que foram caracterizados por Hannah Arendt.

Com o Projeto Escola Livre de Filosofia, a criação de arenas de debate público, sobre questões pertinentes à sociedade, se busca em primeiro lugar uma ação, em segundo lugar reconhecer o outro, em terceiro lugar proporcionar interação e desenvolver um espaço que privilegie as relações em condição de igualdade, em quarto lugar buscamos através do exercício da reflexão e da argumentação, possibilitar o entendimento de cada um a cerca do seu papel enquanto cidadão, quinto lugar educar cada membro para uma postura que seja voltada para espaço de discussão e de argumentação e afastamento completo e total de qualquer tipo de violência, sexto lugar ampliar os espaços públicos para que haja uma interação entre as pessoas, sétimo desenvolver as potencialidades de cada um e despertar em cada um a motivação para participar da vida pública e consequentemente da vida política. Dessa forma acreditamos estar em consonância com o pensamento de Hannah Arendt e em conformidade com os preceitos e valores estabelecidos pela Universidade de Brasília de acordo com a minuta elaborada e acima já mencionada.

Para concluir e buscando uma imagem que possa ainda de forma mais clara expressar aquilo que desejamos, recorro a um livro muito conhecido de todos nós e que prefigura na história da humanidade já há muitos séculos, o "Livro das Mil Uma Noites", como sabemos, nessas narrativas um rei possuído de fúria por ter descoberto a traição de sua mulher, resolve, para não mais sofrer traições, casar-se pela noite e logo ao amanhecer mata-la. O tirânico rei passa a agir dessa forma, deixando em polvorosa todo o reino; até surgir Sherazade, a bela filha do vizir que resolve enfrentar a fúria do rei, pede ela permissão ao seu pai para casar-se, o que consegue com muito custo e 
reprovação de seu pai. Contudo o que ninguém sabe é como fará essa jovem para controlar o ímpeto do rei, Sherazade, passa a noite com o rei e após satisfazê-lo, ela usa de uma artimanha para evitar a sua violência; ela narra para ele histórias fantásticas que faz com que o rei fique entretido, e assim motivado pela sua curiosidade ele não mata a jovem, pois deseja saber o que irá acontecer e qual será o desfecho da narrativa. Ou seja, Sherazade, usa do poder da palavra, da narrativa, da oratória, da retórica, para persuadir o rei, Sherazade fala, usa de argumentação para evitar a violência, para evitar o despotismo, para evitar totalitarismo de um rei, ela usa desse artifício para impedir a brutalidade, é como se ela representasse a política, o conhecimento, o empenho dos seres humanos com a finalidade de impedir, barrar o avanço da ignorância, da brutalidade e da desumanização. Discursar, como nos falou Hannah Arendt, é uma das características específicas dos seres humanos, é exatamente isso que Sherazade, faz, através dos seus discursos ela revive a política com a sua finalidade mais elementar, ou seja, a de colocar os seres humanos, em condição de igualdade e de respeito mútuo, de fazer com que os seres humanos evitem a violência e a brutalidade de um sobre os outros.

Acreditamos ser esse o fundamento motivador de Hannah Arendt, pensadora que vivenciou os horrores da guerra, da perseguição, da ignorância e da brutalidade, mas que buscou através da sua obra, resgatar aquilo que há de mais primordial nos seres humanos a sua capacidade de refletir, de agir, de dialogar e de encontrar soluções para seus conflitos, sem ter que recorrer à barbárie.

Nós do Projeto Escola Livre de Filosofia, seguimos essa mesma linha de raciocínio e não entendemos, como e nem por que em pleno século XXI a humanidade, ainda tenha que conviver, com atrocidades inenarráveis de violência. Violência, muitas vezes cometida, por quem deveria garantir a nossa segurança e vida, falo aqui da violência exercida pelo Estado. É contra a violência existente no Brasil e em diversos países, que nós do projeto acreditamos no nosso trabalho, é contra as imagens da ofensiva de Israel sobre a Palestina, que acreditamos, no diálogo contra a violência, é contra a violência Urbana, contra a violência doméstica, contra a violência praticada em crianças, é contra a violência à mulher, aos homossexuais, à população indígena, aos negros, é contra a todo tipo de violência e humilhação sofrida pelos seres humanos em diversas épocas, em diferentes regiões, que nos motiva a levar a frente o nosso projeto e que nos trouxe até aqui na Unifesp, para participarmos e contribuirmos nessa arena de 
debate e discussão e para que possamos dialogar, trocar experiências e conhecimento, aprendermos e também ensinarmos e assim de forma absoluta afastarmos a violência a tirania e construirmos juntos uma sociedade verdadeiramente igualitária. Resgatando fundamentos e princípios fundamentais da polis grega e cada vez mais entrarmos em consonância com o pensamento de Hannah Arendt.

\section{BIBLIOGRAFIA:}

Minuta Da Câmara De Extensão Univesrsidade De Brasília Disponível Em (Http://Www.Unb.Br/Administracao/Decanatos/Dex/Camara_Extensao.Html)

Oliveira, Luciano (2013): 10 Lições Sobre Hannah Arendt.

Maar, Leo Wolfgand (1985): O Que É Política.

Arendt, Hannah (2007): A Condição Humana.

Jarouche, Mustafa Mamede (2005): Livro Das Mil E Uma Noites: Vol I- Ramo Sírio. 